\title{
Relationship between oral transit time and functional performance in motor neuron disease
}

\author{
Relação entre tempo de trânsito oral e desempenho funcional na doença do neurônio motor \\ Bárbara Carolina BRANDÃO1,2, Magali Aparecida Orate Menezes da SILVA², Paula Cristina COLA ${ }^{1,3}$, Roberta \\ Gonçalves da SILVA'
}

\begin{abstract}
Oral phase swallowing impairment in motor neuron disease (MND) is caused by tongue weakness, fasciculation and atrophy, which may compromise oral transit time and total feeding time. Objective: To describe and correlate total oral transit time (TOTT) with functional performance in MND using different food consistencies. Methods: The study was conducted on 20 patients with MND, regardless of type or duration of the disease, of whom nine were excluded due to issues on the videofluoroscopic swallowing images. The remaining 11 patients (nine men and two women) ranged from 31 to 87 years of age (mean: 57 years) with scores on the Penetration Aspiration Scale ranging from $\leq 2$ to $\leq 4$. The Amyotrophic Lateral Sclerosis Functional Rating Scale - revised questionnaire was applied to classify individuals according to global, bulbar and bulbar/respiratory parameters. Videofluoroscopy of swallowing using $5 \mathrm{ml}$ of different consistencies was performed and a quantitative temporal analysis of the TOTT was carried out with the aid of specific software. Results: There was a wide variation in the TOTT within the same food consistency among MND patients. There was a correlation between the TOTT and overall functional performance for the thickened liquid consistency $(r=-0.691)$ and between the TOTT and bulbar performance for the pureed consistency $(r=-0.859)$. Conclusion: Total oral transit time in MND varies within the same food consistency and the longer the TOTT, regardless of food consistency, the lower the functional performance in MND.
\end{abstract}

Keywords: Deglutition; quantitative analysis; deglutition disorders; amyotrophic lateral sclerosis.

\section{RESUMO}

O comprometimento na fase oral da deglutição na doença do neurônio motor (DNM) é ocasionado por fraqueza, fasciculação e atrofia de língua, podendo comprometer o tempo de trânsito oral (TTO) e o tempo total de alimentação. Objetivo: Descrever e relacionar o tempo de trânsito oral total (TTOT) com o desempenho funcional na DNM em distintas consistências de alimento. Métodos: Participaram 20 indivíduos com DNM, independente do tipo ou tempo de doença. Foram incluídos 11 indivíduos, nove homens e duas mulheres, faixa etária de 31 a 87 anos (média de idade de 57 anos) e com Penetration Aspiration Scale (Rosenbek et al., 1996) de $\leq 2$ a $\leq 4$. Foram excluídos nove indivíduos por questões técnicas relacionadas às imagens videofluoroscópicas de deglutição. Aplicado o questionário Amyotrophic Lateral Sclerosis Functional Rating Scale - revised para classificação dos indivíduos de acordo com parâmetros Global, Bulbar e Bulbar/Respiratório. Realizada videofluoroscopia da deglutição com diferentes consistências de alimento no volume de cinco ml e análise quantitativa do TTOT por meio de software específico. Resultados: Houve ampla variação no TTOT dentro da mesma consistência de alimento na DNM. Houve correlação entre o TTOT e o desempenho funcional global na consistência líquida espessada $(r=-0,691)$ e para o TTOT e o desempenho bulbar na pastosa $(r=-0,859)$. Conclusão: 0 tempo de trânsito oral total na DNM varia dentro da mesma consistência de alimento e quanto mais longo o TTOT, independente da consistência do alimento, menor foi o desempenho funcional na DNM.

Palavras-chave: Deglutição; análise quantitativa; transtornos de deglutição; esclerose lateral amiotrófica.

The prevalence of oropharyngeal dysphagia is approximately $60 \%$ in patients with motor neuron disease (MND). This is a frequent symptom, especially in individuals with bulbar involvement, due to the initial

\footnotetext{
'Universidade Estadual Paulista, Centro de Pesquisa e Reabilitação em Disfagia do Departamento de Fonoaudiologia, Marília SP, Brasil;

${ }^{2}$ Faculdade de Medicina de São José do Rio Preto, Hospital de Base, São José do Rio Preto SP, Brasil;

${ }^{3}$ Universidade de Marília, Marília SP, Brasil.

Bárbara Carolina Brandão (iD) https://orcid.org/0000-0002-5956-5829; Roberta Gonçalves da Silva iD https://orcid.org/0000-0002-2016-3566; Paula Cristina Cola (iD) https://orcid.org/0000-0002-7010-5874; Magali Aparecida Orate Menezes da Silva (iD) https://orcid.org/0000-0002-8238-6343 Correspondence: Bárbara Carolina Brandão; Av. Brigadeiro Faria Lima, 5416 - Vila São Pedro; 15090-000 São José do Rio Preto SP, Brasil; E-mail: babicbrandao@yahoo.com.br

Conflict of interest: There is no conflict of interest to declare.

Received 01 August 2018; Received in final form 09 April 2019; Accepted 01 May 2019
} 
impairment of lower motor neurons ${ }^{1}$. Motor neuron disease is a generic term used to include four clinical syndromes, depending on the primary site of involvement of motor neurons ${ }^{2,3,4}$.

Considering that oropharyngeal dysphagia is one of the critical symptoms of MND leading to malnutrition, dehydration, pneumonia, reduced quality of life and even death, swallowing should be evaluated early, and the involvement of swallowing phases should be monitored over the progression of the disease, to improve behaviors that minimize complications and promote quality of life in this population ${ }^{5,6,7,8}$. Oropharyngeal dysphagia in MND can be diagnosed by videofluoroscopy of swallowing even before bulbar symptoms appear clinically, representing an essential examination for the management of dysphagia in this population $^{9,10}$. Deterioration of the oral phase of swallowing in MND is one of the initial and relevant signs caused by tongue weakness, fasciculation and atrophy, leading to tongue paralysis with the progression of the disease, and causing oral incoordination and longer oral transit time $(\mathrm{OTT})^{11}$. For some authors, early analysis of the oral phase of swallowing in MND, even in individuals with the spinal type who do not have symptoms during early phases of the disease, could help with the diagnosis and prognosis of dysphagia in this population ${ }^{1,12,13}$

In addition to oropharyngeal dysphagia, with an initial impact on the oral phase of swallowing, upper motor neuron and lower motor neuron involvement affect countless other activities of daily living in patients with MND, impairing the overall functionality of this population. It is known that the clinical changes occurring in MND affect the voluntary musculature, functionally compromising the motor and respiratory system and leading to difficulty/incapacity in performing activities of daily living, including feeding and swallowing ${ }^{5,14}$. Therefore, understanding oropharyngeal dysphagia in the context of functional performance in MND could aid the decisionmaking process after patient evaluation.

Some studies that have analyzed oropharyngeal dysphagia in MND, concluding that this symptom could be a predictive factor for the identification of disease severity, have used only qualitative swallowing findings ${ }^{1,5,9,15,16,17}$. To date, no studies have carried out a quantitative temporal analysis of the oral phase of swallowing in MND, a fact that makes the present study a pioneer in this population.

The above-mentioned qualitative studies of swallowing correlated some videofluoroscopic findings with functional performance in MND and found that, with the advancement of MND, worsening of the qualitative parameters of swallowing also occurred, generating significant changes in the swallowing dynamics with consequent risks for laryngotracheal penetration or aspiration, dehydration, and aspiration pneumonia ${ }^{1,13,18}$.
The objective of the present study was to describe and correlate the total oral transit time (TOTT) with functional performance in MND using different food consistencies.

\section{METHODS}

The research project was approved by the Research Ethics Committee of the institution by number 1.619.385. Individuals included in the survey and/or their legal representatives gave written informed consent to participate.

\section{Patient series}

Twenty MND patients, regardless of type or time of disease (mean time of MND diagnosis: three years and six months), diagnosed after clinical and objective examinations at the Neuromuscular Disease Outpatient Clinic of the Hospital de Base de São José do Rio Preto, participated in this study. Nine individuals were excluded due to technical issues related to the swallowing imaging. A total of 11 individuals were included in the final analysis, nine men and two women, aged 31-87 years (mean of 57 years), as described in Table 1, with a Penetration Aspiration Scale ${ }^{18}$ score from $\leq 2$ to $\leq 4$.

\section{Functional performance analysis}

All participants or relatives responded to the Amyotrophic Lateral Sclerosis Functional Rating Scale Revised $^{19}$ applied by a speech-language pathologist in the form of an interview in a private room. The interviewer read the options to the patients and/or caregivers, took note of the response and subsequently performed the analysis of the results of the scale, ensuring the standardization of the evaluation. The scale comprises 12 items related to bulbar function (speech, salivation and swallowing), fine

Table 1. Demographic aspects of motor neuron disease patients.

\begin{tabular}{lcccc}
\hline Variable & Sex & Age & Diagnosis & Time* \\
\hline 1 & M & 87 & ALS/PBP & 1.5 years \\
\hline 2 & M & 58 & ALS & 6 months \\
\hline 3 & M & 57 & ALS & 6 months \\
\hline 4 & F & 51 & ALS & 10 years \\
\hline 5 & M & 31 & ALS & 2 years \\
6 & M & 47 & ALS familial & 6 years \\
7 & M & 57 & ALS & 10 years \\
\hline 8 & M & 59 & ALS & 1 year \\
9 & M & 64 & ALS & 1 year \\
10 & M & 49 & ALS & 6 months \\
11 & F & 67 & ALS & 6 years \\
\hline
\end{tabular}

*Time of diagnosis of MND. MND: motor neuron disease; ALS: amyotrophic lateral sclerosis; PBP: progressive bulbar palsy 
motor function (writing, cutting food/manipulating utensils, dressing and hygiene), gross motor function (turning in bed/adjusting bedding and climbing stairs) and respiratory function (orthopnea and respiratory insufficiency). The score varies from zero to four for each item, resulting in a total score from zero (disability) up to a maximum of 48 points (normal functionality).

\section{Quantitative temporal analysis of swallowing}

A videofluoroscopic evaluation of swallowing was performed in the radiology sector of the Hospital de Base de São José do Rio Preto. The individuals remained seated and the images were obtained in the lateral position, with upper and lower limits extending from the oral cavity to the esophagus, with the anterior limit marked by the lips, the posterior limit by the pharyngeal wall, the upper limit by the nasopharynx, and the lower limit by the cervical esophagus ${ }^{20}$. A remotecontrolled X-ray apparatus (Flexavision- Shimadzu, model $\mathrm{HB}$ ) coupled to a high-resolution VGA converter was used for the analysis.

The following items were used to prepare the consistencies offered to the patients: pureed consistency: $40 \mathrm{ml}$ of water $+15 \mathrm{ml}$ of barium sulphate +1 measure $(4 \mathrm{~g})$ of food thickener; thickened liquid consistency: $20 \mathrm{ml}$ of water $+20 \mathrm{ml}$ of barium sulphate; thin liquid consistency: $40 \mathrm{ml}$ of water $+15 \mathrm{ml}$ of barium sulphate. The three types of consistency were offered on a plastic spoon with a volume of $5 \mathrm{ml}$ each. Three $5 \mathrm{ml}$ portions of each consistency were given to the patients, and interrupted if there was laryngotracheal aspiration.

Images were captured at an acquisition rate of 30 frames per second, thus assessing the position of the bolus approximately every 33 milliseconds. The examinations were scanned and edited on the computer for quantitative analysis of oropharyngeal swallowing with software specifically developed for this purpose ${ }^{21}$.

In this study, the TOTT was defined as the interval in milliseconds between the first frame showing the food inside the oral cavity and the first frame showing the proximal part of the bolus in the final region of the hard palate and beginning of the soft palate, not exceeding the lower portion of the mandible, as proposed by Logemann et al. ${ }^{22}$ and adapted by Gatto et al. ${ }^{23}$. The TOTT of the pureed consistency was measured in ten individuals, the TOTT of the thickened liquid consistency in nine individuals, and the TOTT of the thin liquid consistency in eight individuals.

The results were analyzed by calculating the frequency distribution, percentages, and summarized descriptive statistics, and are presented in the tables and in graphs of individual values. Means of incomplete data were compared by analysis of variance, assuming a level of significance of $\alpha=0.05$; and Pearson's correlation coefficient was calculated for two-dimensional analysis. The Minitab v.16 software was used as computational support.

\section{RESULTS}

Table 2 shows the means and standard deviations of the TOTT for each food consistency per individual with MND, also shown in Figure 1.

Table 2 shows a greater variation in the TOTT for the pasty consistency ( 1,195 to $4,337 \mathrm{~ms})$ than for the other food consistencies $(p=0.012)$. The discrepant point (9,158 ms) was removed from the analysis. Figure 1 illustrates the distribution of mean TOTT values per individual for each food consistency.

Table 3 shows the means, standard deviations and medians for the global, bulbar and bulbar/respiratory functional performance in MND, with individual distribution illustrated in Figure 2.

Table 2. Description of means and standard deviations of the TOTT (ms) per food consistency and per individual.

\begin{tabular}{|c|c|c|c|}
\hline \multicolumn{4}{|l|}{ TOTT (ms) } \\
\hline $\begin{array}{l}\text { Individual } \\
(n=11)\end{array}$ & $\begin{array}{l}\text { Pureed } \\
(n=10)\end{array}$ & $\begin{array}{l}\text { Thickened liquid } \\
\qquad(\mathrm{n}=9)\end{array}$ & $\begin{array}{l}\text { Liquid } \\
(\mathrm{n}=8)\end{array}$ \\
\hline 1 & $9,158 * * *$ & 2,057 & - \\
\hline 2 & 1,457 & $584 * *$ & $433 * \star$ \\
\hline 3 & 3,87 & 1,159 & 2,413 \\
\hline 4 & 2,079 & 1,223 & 1,49 \\
\hline 5 & 1,943 & - & 1,935 \\
\hline 6 & - & $2,729 *$ & $2,677 *$ \\
\hline 7 & 1,94 & 767 & 634 \\
\hline 8 & 2,986 & - & - \\
\hline 9 & $1,195 * \star$ & 734 & - \\
\hline 10 & 1,284 & 1,262 & 2,224 \\
\hline 11 & $4,337 *$ & 1,473 & 1,701 \\
\hline Mean & 2,343 & 1,332 & 1,688 \\
\hline SD & 1,137 & 687 & 809 \\
\hline
\end{tabular}

$\mathrm{N}$ : number of individuals; TOTT: total oral transit time; ms: milliseconds; SD: standard deviation; * Longer TOTT; **Shorter TOTT per food consistency; $* * *$ p-value $($ ANOVA $)=0.012$.

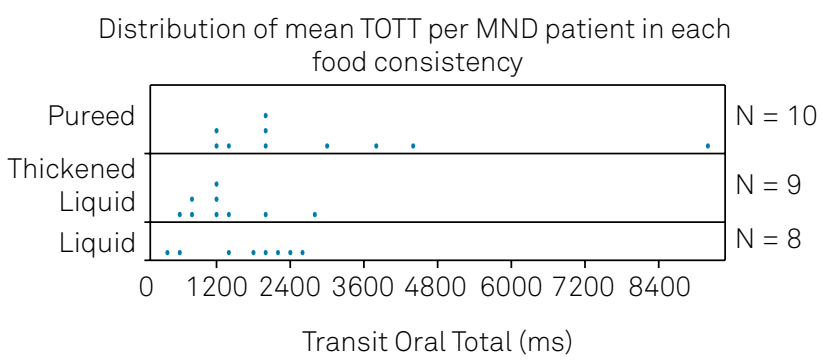

$\mathrm{N}$ : number of individuals; ms: milliseconds; (symbol) - MND patients.

Figure 1. Distribution of mean TOTT per MND patient in each food consistency. 
Table 3. Means, standard deviations, and medians of functional performance in MND patients.

\begin{tabular}{|c|c|c|c|c|c|c|}
\hline Variable & Mean & SD & CV (\%) & Minimum & Median & Maximum \\
\hline ALSFRS-r global $(0-48)$ & 34.4 & 9.1 & 26.4 & 15 & 33 & 46 \\
\hline ALSFRS-r bulbar $(0-12)$ & 8.9 & 2.8 & 31.1 & 2 & 9 & 12 \\
\hline ALSFRS-r bulbar-respiratory $(0-24)$ & 19.3 & 3.9 & 20.4 & 11 & 19 & 24 \\
\hline
\end{tabular}

ALSFRS-r: Amyotrophic lateral sclerosis functional rating scale - revised; SD: standard deviation; CV: coefficient of variation.

Distribution of MND patients according to the score in each parameter of the functional performance evaluation

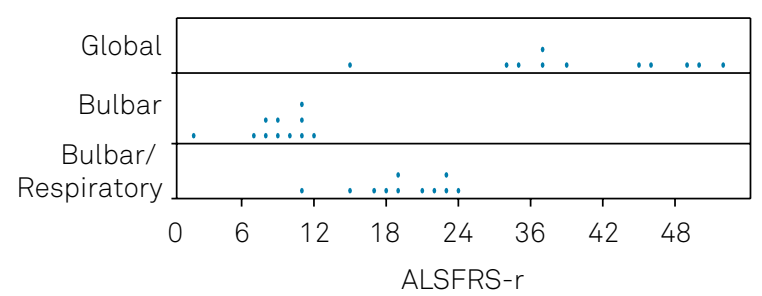

ALSFRS-r: Amyotrophic lateral sclerosis functional rating scale revised; MND patients; individuals with lower functionality in bulbar and bulbar/respiratory parameters; individuals with lower global functionality and greater bulbar and bulbar/respiratory functionality.

Figure 2. Distribution of MND patients according to the score in each parameter of the functional performance evaluation.
Figures 3 to 5 show the correlation between TOTT and functional performance (global, bulbar and bulbar/respiratory) in MND per individual and per food consistency.

\section{DISCUSSION}

Oral transit time is one of the least studied and most controversial parameters of quantitative temporal analyses ${ }^{25,26}$. This statement about the study of OTT is based on many considerations, among them the definition of the beginning and of the end of the oral phase of swallowing, considering the voluntary component exclusively present in this phase of deglutition. The definition of OTT used in most studies was

\section{PUREED CONSISTENCY}

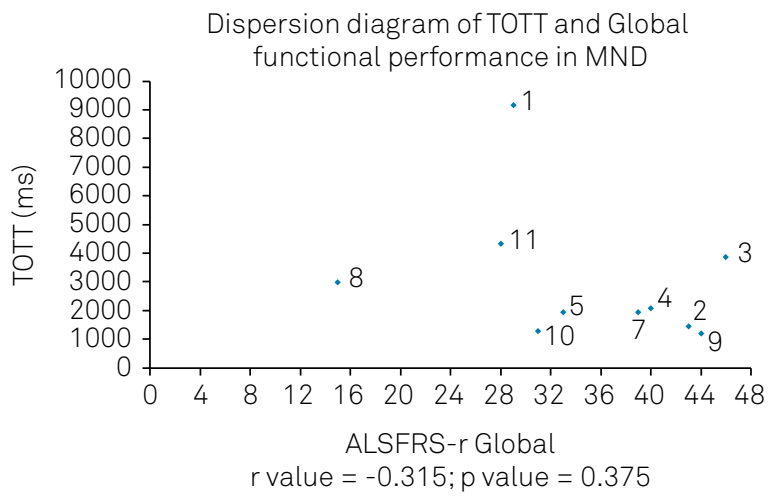

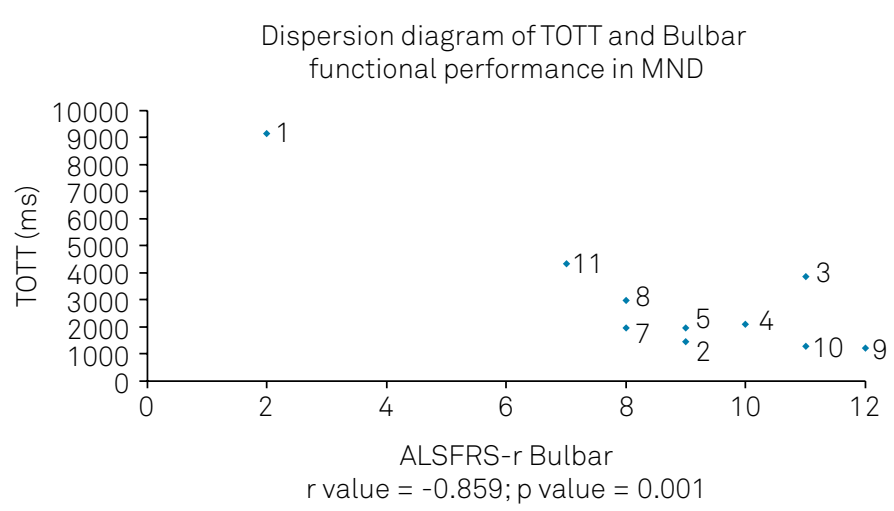

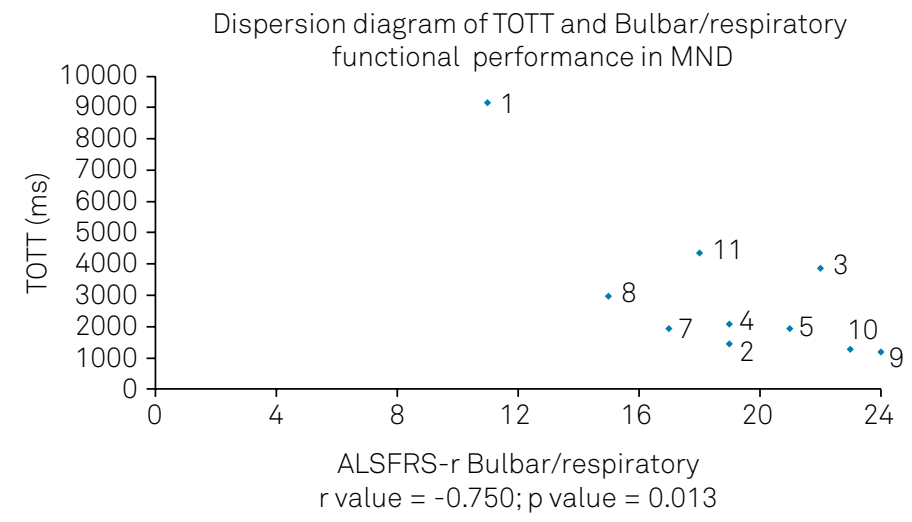

ALSFRS-r Global: $r$ value $=-0.315 ; p$ value = 0.375; ALSFRS-r Bulbar: $r$ value = -0.859; $p$ value = 0.001; ALSFRS- $r$ bulbar/respiratory: $r$ value = -0.750; $\mathrm{p}$ value $=0.013$. TOTT: total oral transit time; MND: motor neuron disease.

Figure 3. Correlation between the TOTT and functional performance (Global, Bulbar, Bulbar/Respiratory) per individual in the pureed consistency 


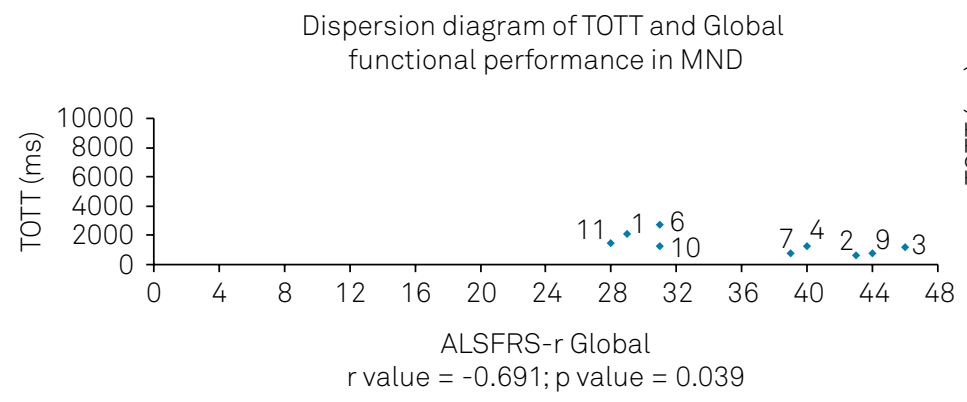

spersion diagram of TOTT and Globa

$=-0.691 ;$ p value $=0.039$

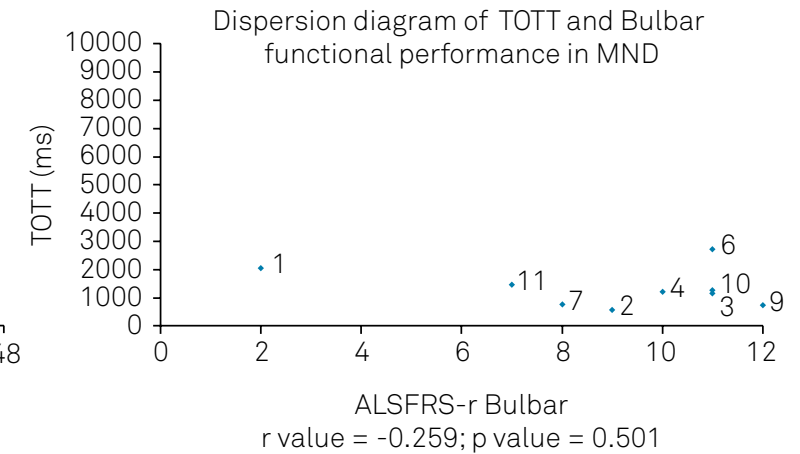

rvalue $=-0.259 ; p$ value $=0.501$

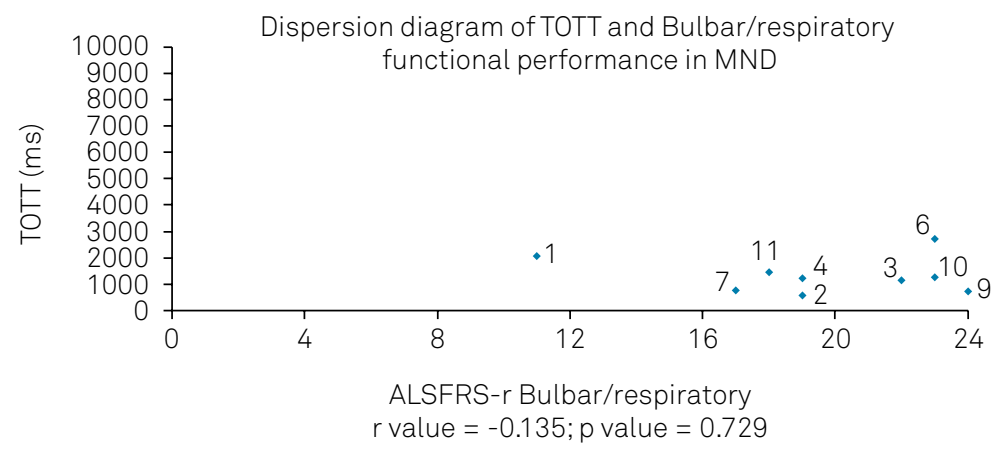

ALSFRS-r global: $r$ value $=-0.691 ; p$ value $=0.039 ;$ ALSFRS- $r$ bulbar $: r$ value $=-0.259 ; p$ value $=0.501 ;$ ALSFRS- $r$ bulbar $/$ respiratory: $r$ value $=-0.135 ; p$ value $=0.729$.

Figure 4. Correlation between the TOTT and functional performance (global, bulbar, bulbar/respiratory) per individual with the thickened liquid consistency.

\section{LIQUID CONSISTENCY}

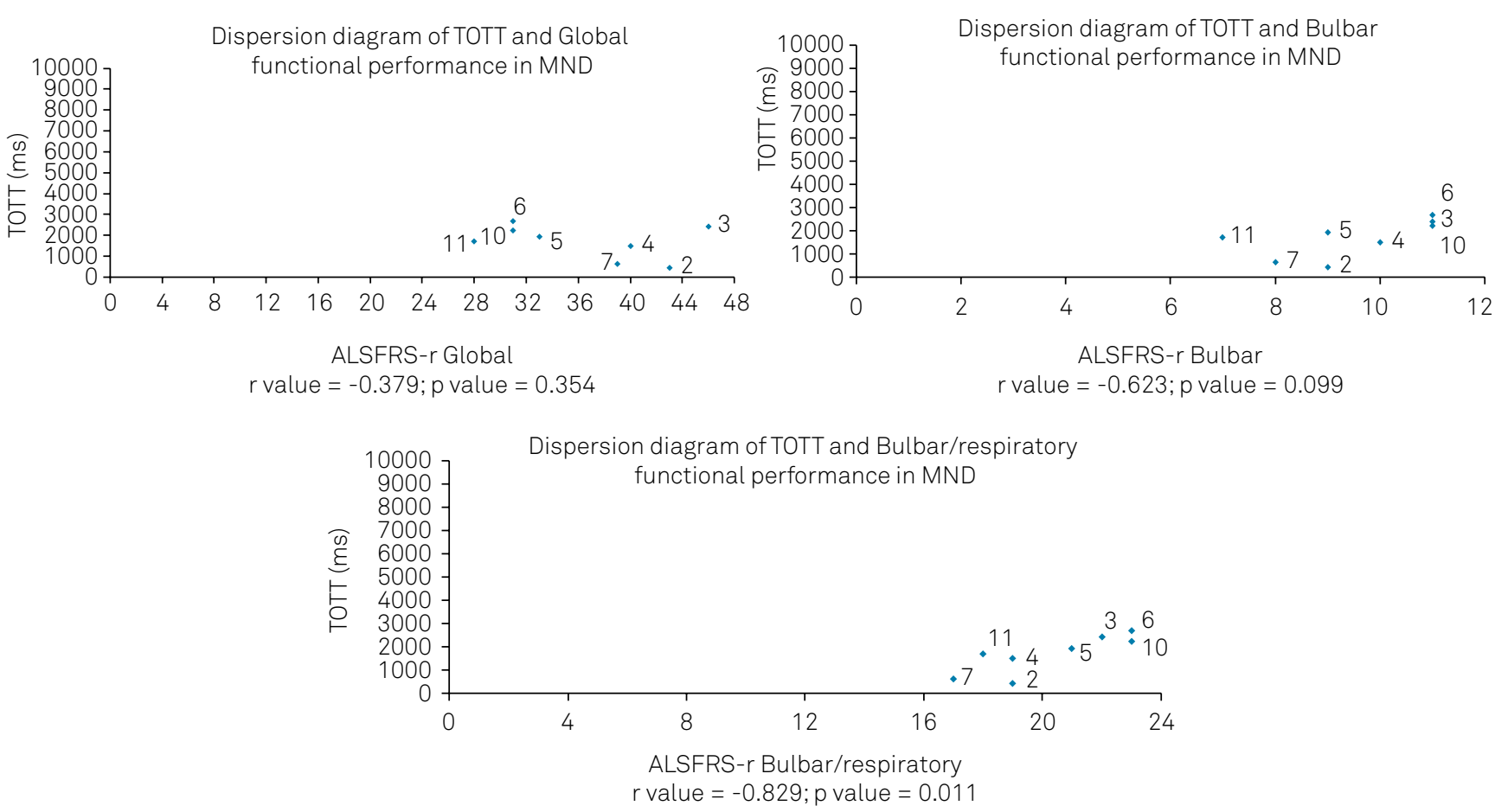

ALSFRS-r global: $r$ value $=-0.379 ; p$ value $=0.354 ;$ ALSFRS- $r$ Bulbar: $r$ value $=-0.623 ; p$ value $=0.099 ;$ ALSFRS- $r$ bulbar $/$ respiratory $: r$ value $=-0.829 ; p$ value $=0.011$.

Figure 5. Correlation between the TOTT and functional performance (global, bulbar, bulbar/respiratory) per individual with the liquid consistency. 
initially described in $1983^{24}$ and complemented in 1995 , by the same author. Since then, the literature has still shown controversies about the definition and initial markers for the measurement of OTT, depending on the author, the study population and the consistency and volume of food ${ }^{27,28,29,30,31,32}$. In the present study, as in other more recent research ${ }^{23,32}$, the definition of the initial marker of OTT considers the fact that the tongue cannot be the only marker of this phase because the time the food remains in the oral cavity, regardless of tongue movements, can impact the total feeding time and efficiency of swallowing.

The first part of the discussion will address the description of TOTT in MND, as this is pioneering work with this population. As shown in Table 2 and Figure 1, the individuals studied showed a wide range of TOTT within the same food consistency. Other authors have described this variation in swallowing times between food consistencies in distinct populations ${ }^{27,28,33-39}$, but there are several factors present in MND that specifically contribute to this result within this population. Although it was not possible to compare our results with other studies analyzing the same population, including the differences in the markers adopted to delimit the oral phase, studies with different dysphagic populations that measured OTT also showed a wide variation in this parameter, suggesting that, in addition to food consistency, the pathophysiology of each disease also interferes with swallowing times ${ }^{28,37}$.

It is possible that the wide variation in the TOTT found in MND is mainly related to the effect of neuromotor impairment of the tongue, soft palate, lips, jaw and pharynx on bolus transport, starting with the oral phase of swallowing in the different stages of the disease $e^{1,5,13}$.

We will discuss separately the functional profile of the studied population as shown in Table 3 and Figure 2 in order to facilitate the understanding of this profile of the sample in future discussions, regarding their relationships with the TOTT. The functionality levels of the MND patients studied here were mostly good, as the patients still walked or had only recently started to use a wheelchair, and were generally less debilitated, non-dependent on alternative exclusive feeding routes and did not require invasive ventilatory support. The difference in functional performance in the population of MND patients has been pointed out by authors who reported that patients with bulbar-onset MND rapidly develop dysarthria and dysphagia but still remain able to walk for a long period of time, while those with spinal onset may develop weakness in the upper and lower limbs and do not present with bulbar symptoms ${ }^{40}$. Therefore, we should take into account that, depending on the form of the disease, bulbar or spinal-onset MND, individuals with initial bulbar involvement are expected to score with lower functionality in the bulbar and respiratory parameters on the Amyotrophic Lateral Sclerosis Functional Rating Scale - revised questionnaire, and score better in the overall parameters. When we observed the distribution of the individuals of this sample among the different levels of functional performance, we noticed a greater variation in the score of global functionality, indicating that, in addition to the TOTT, the level of functional motor performance was variable in these individuals.

At this point of the discussion, we will explore the relationship between functional performance and TOTT for each food consistency, as shown in Figures 3 to 5 . These results showed that for the thickened liquid consistency, the worse the overall functionality, the longer the TOTT. Although it is not possible to discuss this result in comparison with other studies that performed a temporal quantitative analysis of the oral phase of swallowing in the same population, this finding showed that the increase in the TOTT in MND was related to the worsening of functional performance, not only in individuals with bulbar complaints, as pointed out by some authors in studies examining the qualitative performance of the oral phase in this population $^{1,11,12}$. Moreover, this result calls attention to the fact that dysphagia should be evaluated and monitored in MND patients from the initial phase of the disease, regardless of the type, even in individuals who still have good levels of functionality. The increased TOTT in MND could contribute to increasing the total feeding time and end up compromising nutrition, as well as impacting other biomechanical actions of the pharyngeal phase of swallowing.

Regarding the bulbar functional performance and the relation between the TOTT and each food consistency (Figures 3 to 5), it was observed that, with the pasty consistency, the TOTT gradually increased with decreasing bulbar functionality score. This finding is explained by the fact that oropharyngeal dysphagia is more severe from the onset of the disease in MND patients with bulbar involvement due to lower motor neuron and brain stem complications ${ }^{4}$. The viscosity of the food has already been pointed out in the literature as a determining factor influencing the increase in OTT values ${ }^{27},{ }^{28,31}$. It should also be considered that in neurodegenerative diseases in which oral propulsion is affected by muscle weakness, the more pasty the consistency of the food, the greater the need for oral ejection. In MND, oral ejection is markedly compromised in the bulbar form of the disease.

To conclude the discussion about functional performance levels and TOTT, the relationship between the bulbar-respiratory functional performance parameters and the TOTT of each consistency evaluated, as illustrated in Figures 3 to 5, needs to be discussed. The longer the TOTT for the pasty and liquid consistencies, the lower the bulbar-respiratory functionality. It should be borne in mind that individuals who score at lower levels of bulbar-respiratory functionality (speech, salivation, swallowing, dyspnea, orthopnea, and respiratory failure) are the same ones who score at lower levels of bulbar functionality (speech, salivation, and deglutition) only.

Thus, in spite of a wide variation in both the TOTT of the different food consistencies and functional performance 
in its different parameters, this study found a correlation between the TOTT of the pureed and thickened liquid consistency and functional performance in MND patients. This suggests that monitoring the presence of an increase in the TOTT and following the guidelines for intake of pasty food in MND are of fundamental relevance, as when the TOTT is increased, there must be a negative effect on total feeding time, which can compromise nutrition.

We take into account that one of the limitations of the study was the small number of participants, which compromised the results. However, the present study found that even with an Amyotrophic Lateral Sclerosis Functional
Rating Scale - revised score considered to be good, there was an increase in the TOTT regarding specific food parameters and consistencies, as pointed out by other authors reporting qualitative findings of swallowing in $\mathrm{MND}^{1,5,11,15}$. Therefore, we suggest that all patients with a diagnosis of MND, regardless of their functional performance, should be evaluated for oropharyngeal dysphagia immediately after the diagnosis in order to monitor the TOTT and its impact on feeding, nutritional intake, and quality of life.

In conclusion, the TOTT in MND varies within the same food consistency, and the longer the TOTT, regardless of food consistency, the lower the functional performance in MND.

\section{References}

1. Kawai S, Tsukuda M, Mochimatsu I, Enomoto H, Kagesato Y, Hirose $\mathrm{H}$, et al. A study of the early stage of Dysphagia in amyotrophic lateral sclerosis. Dysphagia. 2003;18(1):1-8. https://doi.org/10.1007/s00455-002-0074-3

2. Rowland LP. Diagnosis of amyotrophic lateral sclerosis. J Neurol Sci. 1998 Oct;160 Suppl 1:S6-24. https://doi.org/10.1016/S0022-510X(98)00193-2

3. Swash M, Desai J. Motor neuron disease: classification and nomenclature. Amyotroph Lateral Scler Other Motor Neuron Disord. 2000 Mar;1 (2):105-12. https://doi.org/10.1080/14660820050515403

4. Chieia MA. Doenças do neurônio motor. In: Oliveira ASBO, Oda, AL. Reabilitção nas doenças neuromusculares. São Paulo: Atheneu; 2015 p. 49-77.

5. Higo R, Tayama N, Nito T. Longitudinal analysis of progression of dysphagia in amyotrophic lateral sclerosis. Auris Nasus Larynx. 2004 Sep;31(3):247-54. https://doi.org/10.1016/j.anl.2004.05.009

6. Noh EJ, Park MI, Park SJ, Moon W, Jung HJ. A case of amyotrophic lateral sclerosis presented as oropharyngeal Dysphagia.J Neurogastroenterol Motil. 2010 Jul;16(3):319-22. https://doi.org/10.5056/jnm.2010.16.3.319

7. Goyal NA, Mozaffar T. Respiratory and nutritional support in amyotrophic lateral sclerosis. Curr Treat Options Neurol. 2014 Feb;16(2):270. https://doi.org/10.1007/s11940-013-0270-5

8. Keage M, Delatycki M, Corben L, Vogel A. A systematic review of self-reported swallowing assessments in progressive neurological disorders. Dysphagia. 2015 Feb;30(1):27-46. https://doi.org/10.1007/s00455-014-9579-9

9. Ertekin C, Aydogdu I, Yüceyar N, Kiylioglu N, Tarlaci S, Uludag B. Pathophysiological mechanisms of oropharyngeal dysphagia in amyotrophic lateral sclerosis. Brain. 2000 Jan;123(Pt 1):125-40. https://doi.org/10.1093/brain/123.1.125

10. Fattori B, Grosso M, Bongioanni P, Nacci A, Cristofani $\mathrm{R}$, AlSharif A, et al. Assessment of swallowing by oropharyngoesophageal scintigraphy in patients with amyotrophic lateral sclerosis. Dysphagia. 2006 Oct;21(4):280-6. https://doi.org/10.1007/s00455-006-9052-5

11. Murono S, Hamaguchi T, Yoshida H, Nakanishi Y, Tsuji A, Endo K, et al. Evaluation of dysphagia at the initial diagnosis of amyotrophic lateral sclerosis. Auris Nasus Larynx. 2015 Jun;42(3):213-7. https://doi.org/10.1016/j.anl.2014.10.012

12. Tabor L, Gaziano J, Watts S, Robison R, Plowman EK. Defining swallowing-related quality of life profiles in individuals with amyotrophic lateral sclerosis. Dysphagia. 2016 Jun;31(3):376-82. https://doi.org/10.1007/s00455-015-9686-2
13. Kühnlein P, Gdynia HJ, Sperfeld AD, Lindner-Pfleghar B, Ludolph AC, Prosiegel M, et al. Diagnosis and treatment of bulbar symptoms in amyotrophic lateral sclerosis. Nat Rev Neurol. 2008 Jul;4(7):366-74. https://doi.org/10.1038/ncpneuro0853

14. Goeleven A, Robberecht W, Sonies B, Carbonez A, Dejaeger E. Manofluorographic evaluation of swallowing in amyotrophic lateral sclerosis and its relationship with clinical evaluation of swallowing. Amyotroph Lateral Scler. 2006 Dec; 7(4):235-40. https://doi.org/10.1080/17482960600664870

15. Ruoppolo G, Schettino I, Frasca V, Giacomelli E, Prosperini L, Cambieri C, et al. Dysphagia in amyotrophic lateral sclerosis: prevalence and clinical findings. Acta Neurol Scand. 2013 Dec;128(6):397-401. https://doi.org/10.1111/ane.12136

16. Plowman EK, Watts SA, Robison R, Tabor L, Dion C, Gaziano J, et al. Voluntary cough airflow differentiates safe versus unsafe swallowing in amyotrophic lateral sclerosis. Dysphagia. 2016 Jun;31(3):383-90. https://doi.org/10.1007/s00455-015-9687-1

17. Paris G, Martinaud O, Hannequin D, Petit A, Cuvelier A, Guedon $E$, et al. Clinical screening of oropharyngeal dysphagia in patients with ALS. Ann Phys Rehabil Med. 2012 Dec;55(9-10):601-8. https://doi.org/10.1016/j.rehab.2012.10.005Tabor L,

18. Rosenbek JC, Robbins JA, Roecker EB, Coyle JL, Wood JL. A penetration-aspiration scale. Dysphagia. 1996;11(2):93-8. https://doi.org/10.1007/BF00417897

19. Guedes K, Pereira C, Pavan K, Valério BC. Cross-cultural adaptation and validation of als Functional Rating Scale-Revised in Portuguese language. Arq Neuropsiquiatr. 2010 Feb;68(1):44-7. https://doi.org/10.1590/S0004-282X2010000100010

20. Martin-Harris B, Jones B. The videofluorographic swallowing study. Phys Med Rehabil Clin N Am. 2008 Nov;19(4):769-85. https://doi.org/10.1016/j.pmr.2008.06.004

21. Spadotto AA, Gatto AR, Cola PC, Montagnoli AN, Schelp AO, Silva RG, et al. Software para análise quantitativa da deglutição. Radiol Bras. 2008;41(1):25-8. https://doi.org/10.1590/S0100-39842008000100008.

22. Logemann JE. Evaluation and treatment of swallowing disorders. City: San Diego: College Hill; 1983.

23. Gatto AR, Cola PC, Silva RG, Spadotto AA, Ribeiro PW, Schelp $A O$, et al. Sour taste and cold temperature in the oral phase of swallowing in patients after stroke. CoDAS. 2013;25(2):164-8. https://doi.org/10.1590/S2317-17822013000200012

24. Soares TJ, Moraes DP, Medeiros GCD, Sassi FC, Zilberstein B, Andrade CRFD. (2015). Oral transit time: a critical review of the literature. ABCD. Arq Bras Cir Dig. 2015 Apr.-Jun;28(2):144-7. https://doi.org/10.1590/s0102 67202015000200015 
25. Molfenter SM, Steele CM. Temporal variability in the deglutition literature. Dysphagia. 2012 Jun;27(2):162-77. https://doi.org/10.1007/s00455-012-9397-x

26. Logemann JA, Pauloski BR, Colangelo L, Lazarus C, Fujiu M, Kahrilas PJ. Effects of a sour bolus on oropharyngeal swallowing measures in patients with neurogenic dysphagia. J Speech Hear Res. 1995 Jun;38(3):556-63. https://doi.org/10.1044/jshr.3803.556

27. Dantas RO, Kern MK, Massey BT, Dodds WJ, Kahrilas PJ, Brasseur $J G$, et al. Effect of swallowed bolus variables on oral and pharyngeal phases of swallowing. Am J Physiol. 1990 May;258(5 Pt 1):G675-81. https://doi.org/10.1152/ajpgi.1990.258.5.G675

28. Dantas RO, de Aguiar Cassiani R, dos Santos CM, Gonzaga GC, Alves LM, Mazin SC. Effect of gender on swallow event duration assessed by videofluoroscopy. Dysphagia. 2009 Sep;24(3):280-4. https://doi.org/10.1007/s00455-008-9202-z

29. Bingjie L, Tong Z, Xinting S, Jianmin X, Guijun J. Quantitative videofluoroscopic analysis of penetration-aspiration in post-stroke patients. Neurol India. 2010 Jan-Feb;58(1):42-7. https://doi.org/10.4103/0028-3886.60395

30. Kim SY, Kim TU, Hyun JK, Lee SJ. Differences in videofluoroscopic swallowing study (VFSS) findings according to the vascular territory involved in stroke. Dysphagia. 2014 Aug;29(4):444-9. https://doi.org/10.1007/s00455-014-9525-X

31. Wakasugi Y, Yamamoto T, Oda C, Murata M, Tohara H, Minakuchi S. Effect of an impaired oral stage on swallowing in patients with Parkinson's disease. J Oral Rehabil. 2017 Oct;44(10):756-62. https://doi.org/10.1111/joor.12536

32. Lof GL, Robbins J. Test-retest variability in normal swallowing. Dysphagia. 1990;4(4):236-42.
33. Im I, Kim Y, Oommen E, Kim H, Ko MH. The effects of bolus consistency in pharyngeal transit duration during normal swallowing. Ann Rehabil Med. 2012 Apr;36(2):220-5. https://doi.org/10.5535/arm.2012.36.2.220

34. Cola P, Gatto AR, da Silva RG, Spadotto AA, Ribeiro PW, Schelp $A O$, et al. Taste and temperature in swallowing transit time after stroke. Cerebrovasc Dis Extra. 2012 Jan;2(1):45-51. https://doi.org/10.1159/000339888.

35. Lustre NDS, Freire TRB, Silvério CC. (2013). Temporal measurements of oral transit time in children with cerebral palsy of different levels motors and the relationship with the severity of dysphagia. Audiol Commun Res, 2013;18(3):155-61. https://doi.org/10.1590/S2317-64312013000300004

36. Lee SI, Yoo JY, Kim M, Ryu JS. Changes of timing variables in swallowing of boluses with different viscosities in patients with dysphagia. Arch Phys Med Rehabil. 2013 Jan;94(1):120-6. https://doi.org/10.1016/j.apmr.2012.07.016

37. Nagy A, Molfenter SM, Péladeau-Pigeon M, Stokely S, Steele $\mathrm{CM}$. The effect of bolus consistency on hyoid velocity in healthy swallowing. Dysphagia. 2015 Aug;30(4):445-51. https://doi.org/ 10.1007/s00455-015-9621-6

38. Zhang J, Zhou Y, Wei N, Yang B, Wang A, Zhou H, et al. Laryngeal elevation velocity and aspiration in acute ischemic stroke patients. PLoS One. 2016 Sep 1;11(9):e0162257. https://doi.org/10.1371/journal.pone.0162257

39. Turner MR1, Scaber J, Goodfellow JA, Lord ME, Marsden R, Talbot K. The diagnostic pathway and prognosis in bulbar-onset amyotrophic lateral sclerosis. J Neurol Sci. $2010 \mathrm{Jul}$ 15;294(1-2):81-5. https://10.1016/j.jns.2010.03.028 